\section{A magma mixing redox trap that moderates mass transfer of sulphur and metals}

\section{A. Fiege ${ }^{1,2^{*}}$, P. Ruprecht ${ }^{3}$, A. Simon}

\section{Abstract}

open 2 ACCESS

Mxing and juxtaposition of chemically distinct magmatic systems are key processes for the evolution of Earth's crust. Yet, the physicochemical nature at mixing interfaces remains poorly described, as crystallisation, melting, heat transfer, and diffusion are interconnected and lead to complex mass transfer processes driving unique patterns of element fractionation. Here, we use diffusion couple experiments between felsic and mafic magmas (melt + crystals \pm volatiles) to document the formation of large gradients in oxygen fugacity at the magmamagma mixing interface. Reducing and oxidising boundary layers at the interface develop rapidly and remain in dynamic disequilibrium for days to possibly weeks. We sugest that the observed transient red the requird con he and chalcophile elements and moderate, for example, Cu/Au ratios in arc-related porphyry ore deposits.

Received 26 October 2016 | Accepted 29 March 2017 | Published 15 May 2017

\section{Introduction and Approach}

Magmatic systems in Earth's crust evolve through interplay between magma supply from the mantle and magma withdrawal feeding shallow reservoirs and, ultimately, volcanic eruptions (DePaolo, 1981; Hildreth and Moorbath, 1988, Annen et al., 2006). As a consequence, magma mixing is ubiquitous (Bacon and Metz, 1984; Ruprecht and Bachmann, 2010) and frequently invoked to explain geochemical records of, for example, volcanic gases (Wallace and Gerlach, 1994) and porphyry ore deposits (Audétat and Simon, 2012). Magma mixing processes

. Earth and Environmental Sciences, University of Michigan, 1100 North University Ave, Ann Arbor, MI 48109-1005, USA

Earth and Planetary Sciences, American Museum of Natural History, Central Park West at 79th Street, New York, NY 10024-5192, USA

Corresponding author (email: afiege@amnh.org)

3. Geological Sciences \& Engineering, University of Nevada, 1664 N. Virginia Street, Reno, NV 89557, USA are often discussed in the context of stirring and stretching (Bergantz, 2000 Perugini et al., 2003; Ruprecht et al., 2008); however, homogenisation on all scales requires diffusive exchange along chemical gradients, especially in magma reservoirs with limited convection (Pichavant et al., 2007). These mixing systems are typically characterised by multi-phase (crystal + melt + fluid) sub-liquidus conditions. To date, few experiments have explored the complex interplay of diffusion and phase change(s) at sub-liquidus temperatures (e.g., Watson, 1982; Pistone et al., 2016).
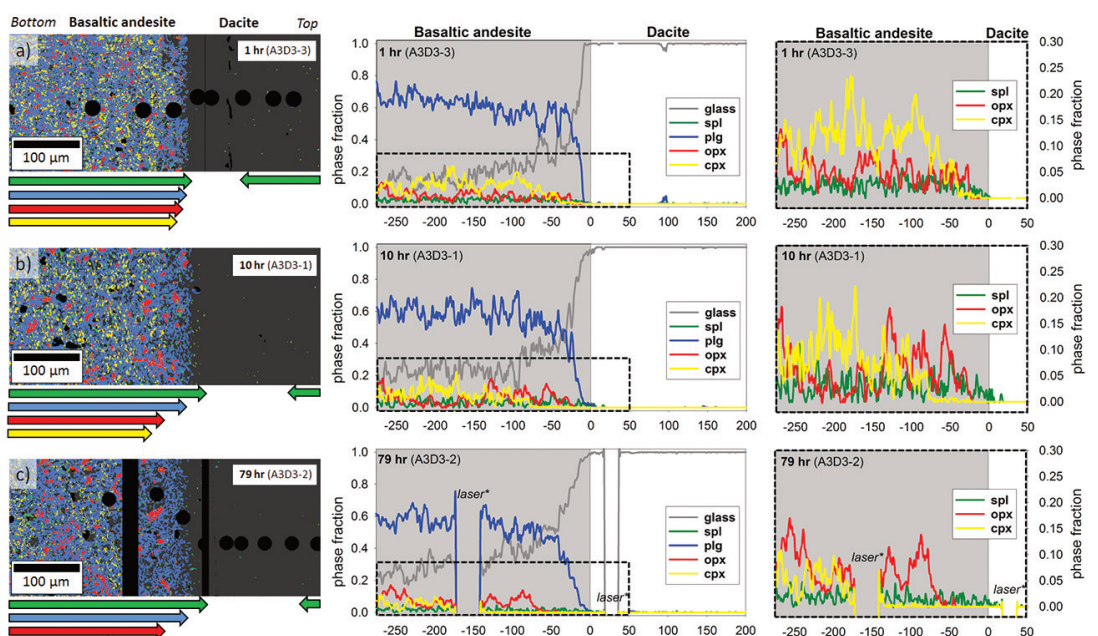

$\begin{array}{ccccc}-100 & -50 & 0 & 50 & 100 \\ \text { Distance to interface }[\mu \mathrm{m}]\end{array}$

Figure 1 Maps and phase fraction plots illustrating the phase assemblages of the run prodigure 1 - Maps and phase fraction plots (top: dacite; bottom: basaltic andesite) (a) 1 hr ru (experiment A3D3-3). (b) $10 \mathrm{hr}$ (A3D3-1): (c) $79 \mathrm{hr}$ (A3D3-2). Left column: WDS (A) $1 \mathrm{hr}$ run $\mathrm{Ca}, \mathrm{K}$ ) and $\mathrm{EDS}$ ( $\mathrm{Si}, \mathrm{Na}$ ) maps were used to produce phase assemblage maps. The "glass only" area (grey) of each diffusion couple grows with time. The arrows below each map indicate the presence of a certain mineral phase away from the basaltic andesite or dacitic far side up until the tip of the respective arrow where green $=$ spinel $($ spl), blue $=$ plagioclase $(\mathrm{plag})$, up un = orthopyroxene (opx), and yellow = clinopyroxene (cpx). Centre and right column: The red $=$ orthopyroxene (opx), and yellow, = clinopyroxene (cpx). Centre and right column: The phase fraction for a cen is a magnification, displaying only the fractions for uspl, 0 in *Position of the vertical laser-ablation transect. For IGSN sample registration see Supplementary Infomation. Phase fractions are provided in Supplementary Information D.

We performed sub-liquidus time-series experiments in rapid-quench cold-seal TZM pressure vessels, which were investigated by micro X-ray absorp tion near-edge structure ( $\boldsymbol{u}$-XANES) spectroscopy at Fe K-edge (Fiege et al, 2017), and two-oxide oxybarometry (Ghiorso and Evans, 2008), to document redox evolution near the magma-magma interface. Hydrous basaltic andesite and dacite cylinders were equilibrated separately at different conditions in gold capsules (basaltic andesite: $1030{ }^{\circ} \mathrm{C}, 1.1$ wt. $\% \mathrm{H}_{2} \mathrm{O}, 1000$ ppm S, 500 ppm $\mathrm{Cl}_{\text {; }}$ 
dacite: $950{ }^{\circ} \mathrm{C}, 3.9$ wt. $\% \mathrm{H}_{2} \mathrm{O}, 100 \mathrm{ppm} \mathrm{S}, 1500 \mathrm{ppm} \mathrm{Cl}$; both at QFM + 4 and $150 \mathrm{MPa}$ ). The capsules were sliced, polished, and loaded into a gold capsule with the basaltic andesite on bottom and the dacite on top. The capsules were sealed with a lid on bottom and star crimped on top. Pre-compression of the capsules ( 100 MPa) resulted in an ideal planar contact between both cylinders due to the star crimping technique. Subsequent mixing experiments $\left(1000{ }^{\circ} \mathrm{C}\right.$, $150 \mathrm{MPa}, \mathrm{QFM}+4,1$ to $79 \mathrm{hr}$ ) reveal a mostly crystal-free dacite. Minor amounts of $\mathrm{Fe}$-Ti-oxides are consumed with time in a growing oxide-free zone near the interface ( $\sim 0$ to 150 um wide; Fig. 1). Meanwhile, crystallinity of the basaltic andesite near the interface $(<150 \mu \mathrm{m})$ decreases continuously with time. During the mixing process, clinopyroxene (cpx) is the first completely resorbed silicate phase, followed by orthopyroxene (opx). Plagioclase (plg) is resorbed significantly near the interface in all experiments, but continues to constitute a rigid crysta network throughout the basaltic andesite. With increasing run duration, concentrations of felsic and mafic components decrease and increase, respectively, in the dacitic melt near the interface (Fig. S-A3). Diffusion profiles were observed for $\mathrm{S}$ (mafic to felsic) and $\mathrm{Cl}$ (felsic to mafic), whereas $\mathrm{H}_{2} \mathrm{O}$ remains constant away from the interface (Supplementary Information A and C).

\section{Determination of Redox Profiles}

Redox-sensitive oxide-pairs (ilmenite, il; and spinel, spl) in the basaltic andesite reveal systematic compositional variations (Fig. 2, Table S-C9); the dacite lacks il, which prevents the application of two-oxide oxybarometry. In $1 \mathrm{hr}$ and $10 \mathrm{hr}$ experiments, $X_{\mathrm{il}}$ (fraction of $\mathrm{FeTiO}_{3}$ in il) and $\mathrm{X}_{\mathrm{uv}}$ (fraction of $\mathrm{TiFe}_{2} \mathrm{O}_{4}$ in spl) decrease from $\sim 0.45$ and $\sim 0.15$ in the basaltic andesite far field to $\sim 0.33$ and $\sim 0.10$ near the interface, respectively. Far field oxide compositions are similar to those in the starting basaltic andesite $\left(X_{\mathrm{il}} \sim 0.44 ; \mathrm{X}_{\mathrm{uv}} \sim 0.13\right)$. The $79 \mathrm{hr}$ experiment shows a more evolved profile, wherein the basaltic andesite interior contains oxides with compositions similar to the $1 \mathrm{hr}$ and $10 \mathrm{hr}$ experiment. A broad (>1500 $\mu \mathrm{m})$ continuous decrease in $\mathrm{X}_{\mathrm{il}}(\sim 0.42$ to $\sim 0.24)$ and $\mathrm{X}_{\mathrm{uv}}(\sim 0.11$ to $\sim 0.05)$ emerges towards the interface. In contrast to the $1 \mathrm{hr}$ and $10 \mathrm{hr}$ profile, a decrease in $\mathrm{X}_{\mathrm{i}}$ $(\sim 0.34)$ and $X_{\text {uv }}(\sim 0.06)$ was measured in the basaltic andesite far field $(>2500 \mu \mathrm{m})$, which is directly related to the $\mathrm{fO}_{2}$ imposed by the experimental apparatus; i.e. an effect not expected in natural systems (see Supplementary Information A). These length scales of $X_{i l}$ and $X_{u v}$ variations are significantly larger than the measured changes in crystallinity $(<150 \mu \mathrm{m}$; Fig. 1), indicating that the observed redox gradient is largely decoupled from crystal resorption rate.

The $\mu$-XANES analyses of the dacitic glass reveal significant changes in Fe oxidation state (Fig. 2b, Tables S-C11 to S-C13) that correlate spatially with $\mathrm{FeO}_{\text {tot }}$ and other melt constituents (Fig. 2b,d). In the $1 \mathrm{hr}$ and $10 \mathrm{hr}$ experiments, $\mathrm{Fe}^{3+} / \Sigma \mathrm{Fe}$ of the dacitic melt decreases by $\sim 23 \%$ from the far field to the interface. The Fe redox profile is relatively flat at $79 \mathrm{hr}$, with a minor decrease of $\mathrm{Fe}^{3+} / \Sigma \mathrm{Fe}$

Basaltic andesite (two-oxides)

Dacite (Fe XANES)
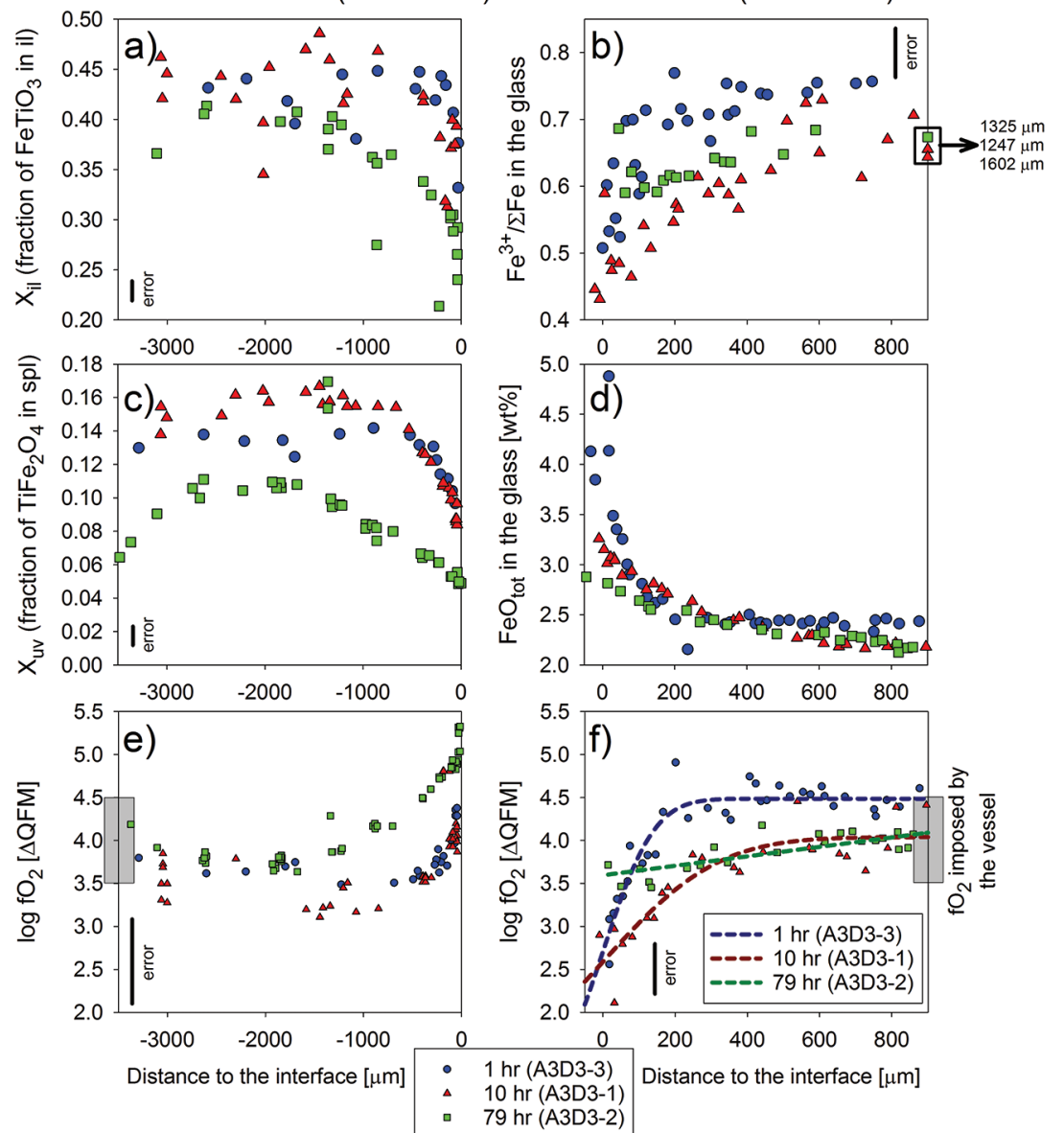

Figure 2 Redox profiles in the dacite and the basaltic andesite determined by $\mathrm{Fe} \mu$-XANES and two-oxide oxybarometry, respectively. (a) Fraction of $\mathrm{TiFe}_{2} \mathrm{O}_{4}$ in $\mathrm{spl}$ vs. distance to the interface. (b) $\mathrm{Fe}^{3+} / \mathrm{Se}$ in dacitic glass vs. distance to the interface. (c) Fraction of $\mathrm{FeTiO}_{3}$ in il vs. distance to the interface. (d) $\mathrm{Fe}_{\text {tot }}$ concentrations in the melt on the dacitic side. (e) $\mathrm{fO}_{2}$ of the interface; $\mathrm{fO}_{2}$ was calculated using Ghiorso and Evans (2008). (f) $\mathrm{fO}_{2}$ of the dacite side vs. distance to the interface; $\mathrm{fO}_{2}$ was predicted using Moretti (2005). For the calculations we used the $\mathrm{Fe}^{3+} / \Sigma \mathrm{Fe}$ ratios determined via XANES and the local glass composition determined via EPMA (Supplementary Information A). The vertical black bars represent the average of $2 \sigma$ errors (Fig. $2 \mathrm{a}-\mathrm{c}$ ): $1 \sigma$ error of the $\mathrm{FeO}_{\text {tot }}$ concentrations in the glasses is $\pm 0.2 \mathrm{wt}$. \% (Fig. $2 \mathrm{~d}$ ). The indicated errors for $\mathrm{fO}_{2}$ represent conservative estimations for the overall uncertainty of the two-oxides ( $\pm 0.5 \mathrm{log}$ units; Fig. $2 \mathrm{e}$ ) and Fe $u$-XANES $\left( \pm 0.2 \mathrm{log}\right.$ units; Fig. 2f) method, respectively. Both methods reproduce the $\mathrm{fO}_{2}$ imposed by the vessel within 0.2 log units for run duration $>10 \mathrm{hr}$, providing an independent constraint for the high accuracy and comparability of the two datasets. 
from $\sim 68 \%$ in the far field to $\sim 60 \%$ near the interface. At $200 \mu \mathrm{m}(1 \mathrm{hr}$ run $)$ and $500 \mu \mathrm{m}(10 \mathrm{hr}$ and $79 \mathrm{hr})$ away from the interface, the profiles remain at constant $\mathrm{Fe}^{3+} / \Sigma \mathrm{Fe}$, whereas the far field of the $1 \mathrm{hr}$ experiments is characterised by a $\sim 6 \%$ higher $\mathrm{Fe}^{3+} / \Sigma \mathrm{Fe}$ compared to the $10 \mathrm{hr}$ and $79 \mathrm{hr}$ runs. The $6 \%$ difference likely results from juxtaposing hotter mafic and cooler felsic magma at intermediate mixing temperatures, simulating nature. Here, fast thermal equilibration decreases $\mathrm{Fe}^{3+} / \Sigma \mathrm{Fe}$ in the cooling mafic melt fraction and increases $\mathrm{Fe}^{3+} / \Sigma \mathrm{Fe}$ within the heating felsic melt. This is confirmed by the far field results (Fig. 2), whereas the buffering capacity of the vessel eliminates this temperature effect with increasing run duration. The small quenched melt pools on the mafic side precluded precise XANES analyses.

Models for $\mathrm{Fe}^{3+} / \Sigma \mathrm{Fe}$ (Fiege et al., 2017) and two-oxide oxybarometry (Ghiorso and Evans, 2008) reveal a zigzag redox trend near the interface (Fig. 2e-f) In particular, we observe a sudden $\mathrm{fO}_{2}$ drop at the interface that increases from $\sim 1.3 \mathrm{log}$ units $\mathrm{fO}_{2}$ after $1 \mathrm{hr}$ and $10 \mathrm{hr}$ to $1.8 \mathrm{log}$ units $\mathrm{fO}_{2}$ after $79 \mathrm{hr}$. Considering the temperature effect on $\mathrm{fO}_{2}$, the far sides of the longest run provide the best estimation of the accuracy of the two methods; i.e. both methods reproduce the local $\mathrm{fO}_{2}$ within $0.2 \log$ units, considering the $\mathrm{fO}_{2}$ imposed by the vesse (QFM + 4; see Fig. 2e,f and Supplementary Information A.4.4). The oxide pairs are within $\leq 50 \mu \mathrm{m}$ of each other relative to the interface and we only considered oxide pairs in $\mathrm{Mg} / \mathrm{Mn}$ equilibrium (Bacon and Hirschmann, 1988).

\section{Discussion of the Redox Mechanism}

Intriguingly, a significant redox gradient at the interface is observed in all run products, reaching $\sim 1.8 \log$ units $\mathrm{fO}_{2}$ after $79 \mathrm{hr}$. Thus, this transient redox gradient may initially grow with time and is of relevance for several days and possibly weeks. In the absence of water diffusion profiles (confirmed by Raman spectroscopy on the dacitic side; see Supplementary Information C), water exchange cannot be responsible for the redox gradient. In magmatic systems, the net redox gradient at the interface may grow with time, considering that our experiments are externally buffered, resulting in a fading redox gradient with increasing run duration, consistent with $\mathrm{H}_{2}$ diffusivities (see Zhang and Ni, 2010; and Supplementary Information A.4.5).

We propose that the redox gradient reflects a transient electron hole gradient that emerges between two mixing magmas as mass is transferred across the interface. The observed mineral resorption sequence of cpx $\rightarrow$ opx $\rightarrow$ plg $(\rightarrow$ oxides; Fig. 1) and concentration maxima at the interface for, e.g., Fe and $\mathrm{Mg}$ (Fig. S-A3) indicate that compatible elements are added to the melt near the interface, inducing a diffusive flux from mafic to felsic magma. Mass transfer of cations, and, in particular, of divalent network modifying cations, requires a counter flux of charge-compensating electron holes $\left(h^{\bullet}\right.$, where the superscript dot indicates a single positive charge), which are the dominant mobile electronic species in Fe-bearing silicate melts (e.g., Cooper et al., 2010; Cooper, 2017).

\section{Basaltic andesite Dacite}

a)

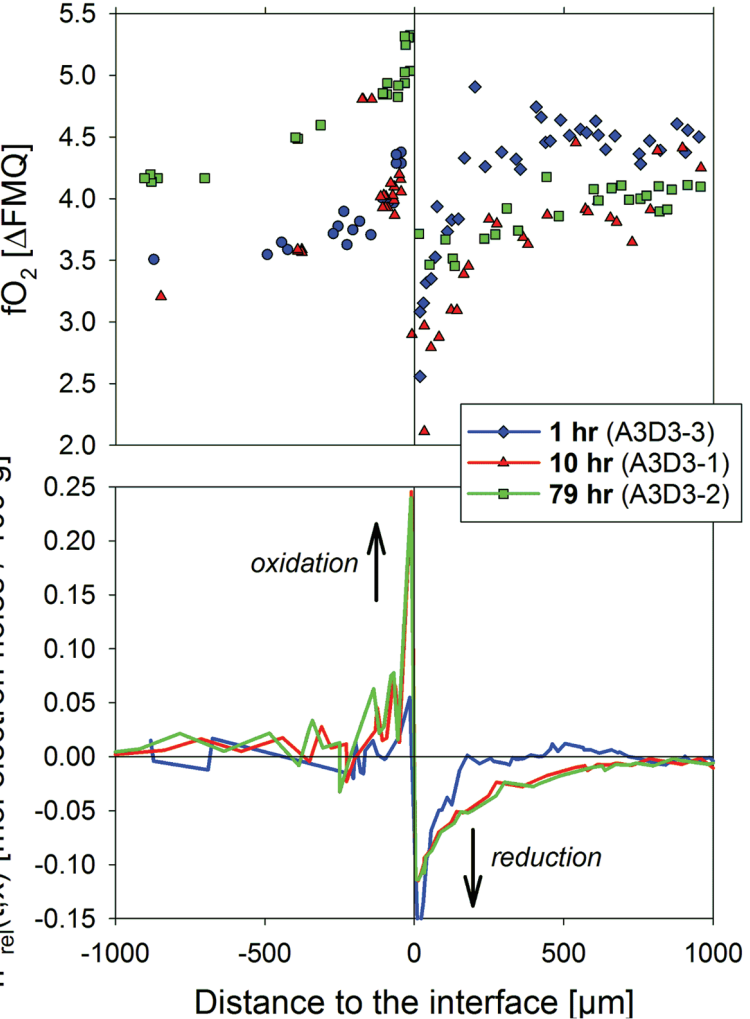

$$
\mathrm{h}_{\text {rel }}^{\cdot}(\mathrm{t}, \mathrm{x})=\sum_{\mathrm{i}=1}^{\mathrm{m}}\left(\frac{\mathrm{f}_{\mathrm{x}} \cdot\left(\mathrm{c}_{\mathrm{t}, \mathrm{i}}^{\mathrm{i}}-\mathrm{c}_{0}^{\mathrm{i}}\right)}{M w^{\mathrm{i}}} \cdot \mathrm{n}^{\mathrm{i}}\right)+\mathrm{h}_{\text {equi }}^{\cdot}
$$

Figure 3 Diffusion-induced redox gradients and estimate of the electron hole disequilibrium of the melt across the interface. (a) Magnification of Figure 2e-f. (b) The trends are calculated using the equation below the figure, where $h_{r e l}(t, x)$ is the relative change in electron holes $(\mathrm{mol} / 100 \mathrm{~g})$ at a distance $x$ to the interface and at a time $t$ integrated diffusive flux, thus, the sum of the concentration differences for each element $i$ with the oxidation state $n$ (e.g., $n=+1$ for $\mathrm{Na}$ and $\mathrm{n}=-1$ for $\mathrm{Cl}$ ) from its initial concentration $\left(\mathrm{c}_{\mathrm{t}, \mathrm{x}}-\mathrm{c}_{0}\right)$. Mw and $\mathrm{ft}_{\mathrm{t}, \mathrm{x}}$ are the molecular weight and the melt fraction, respectively. The melt composition at the far side of the basaltic andesite and the dacite was assumed to represent the zero-time melt composition $\left(c_{0}\right)$. The calculated trends probably represent the maximum diffusion-induced electron hole gradient because we do not account for the effects of simultaneous electron hole equilibration ( $h^{\circ}$ equi), associated, e.g., with $\mathrm{h}^{\circ}$ counter flux, $\mathrm{H}_{2}$ diffusion, and phase change (i.e. mineral dissolution); the latter process is presumably balanced, whereas the first two compensate $h^{\bullet}$ gradients with time. The calculated $\mathrm{h}^{\boldsymbol{*}}$ gradients would allow the oxidation/reduction of up to $10 \mathrm{wt}$. \% Fe near the interface, while we observe a maximum change by $~ 0.8 \mathrm{wt}$. \% Fe (see Supplementary
Information A.4.5). 
This coupled cation - electron hole flux in Fe-bearing silicate melts (Mode III redox; Cook and Cooper, 2000) kinetically dominates redox control relative to other known mechanisms that involve flux of a neutral gas species (e.g., Mode I of Cook and Cooper, 2000; see also Gaillard et al., 2003) and oxygen flux (e.g., Mode II of Cook and Cooper, 2000); the latter mechanism has mostly been ruled out as a diffusive redox control in silicate melts (Cooper et al., 1996; Gaillard et al., 2003).

In a magma-magma mixing environment, the thermodynamic disequilibrium imposed by juxtaposing two chemically distinct systems results in a chemical potential that drives significant mass transfer between both systems (e.g., see Fig. S-A3). Thus, the formation of a redox gradient at a magma-magma interface suggests that the $h^{\bullet}$ counter flux is insufficient to balance the significant mass flux across the interface, indicating rather low $\mathbf{h}^{\bullet}$ concentrations in the studied system (cf. Cooper et al., 2010). This hypothesis can be tested by performing simplified model calculations that consider the relative changes in melt composition on both sides of the diffusion couple as a function of distance to the interface, while ignoring simultaneous electron hole equilibration ( ${ }^{\bullet}{ }_{\text {equij }}$ see Fig. 3, Supplementary Information A.4.5). The estimated $h^{\bullet}$ gradients predict an electron hole enrichment zone (oxidation) in the basaltic andesite near the interface, and an electron hole depletion zone (reduction) in the dacite, mimicking the measured redox variations. Here, the melt $\mathrm{Fe}^{3+} / \Sigma \mathrm{Fe}$ presumably responds immediately to the diffusion-induced electron hole imbalance, while the chemistry of the il-sp oxide pairs will follow those changes with a slight delay. Considering the small size of the oxides (typically $<5 \mu \mathrm{m}$ ), equilibrium with the surrounding melt is reached within $<<10 \mathrm{hr}$ (Freer and Hauptman, 1978). Hence, the redox profiles determined for the basaltic andesite side of the diffusion couples may represent minimum gradients for the $1 \mathrm{hr}$ and the $10 \mathrm{hr}$ experiments, while it probably closely reflects the prevailing redox conditions of the melt in close proximity to the respective crystal pair for the $79 \mathrm{hr}$ experiment. The proposed mechanism is consistent with theoretical considerations of Evans (2006) and studies of redox processes in Fe-bearing magnesium aluminosilicate glasses, and basaltic glasses and melts (e.g., Cooper et al., 1996, 2010).

We note that the release of predominantly ferrous Fe from resorbing cpx and opx (opx: $\mathrm{Fe}^{2+}$; cpx: low $\mathrm{Fe}^{3+} / \Sigma \mathrm{Fe}$ ) may decouple from the initial $\mathrm{fO}_{2}$ and may contribute to the observed $\mathrm{Fe}^{3+} / \Sigma \mathrm{Fe}$ gradient on the dacitic side, but cannot explain the observed zigzag redox trend in full.

\section{Implications of a Magma-Magma Mixing Redox Trap}

The experiments show that a redox gradient can form when two chemically distinct magmas mix across an evolving compositional and textural interface. The net gradient, the stability of the gradient, as well as the spatial extent of the gradient are probably significantly affected by the (pre-)mixing pressure and temperature conditions as well as by the compositions and $\mathrm{fO}_{2}$ of the two mixing magmas. Whether the observed effect of local magma reduction/oxidation is of importance on a larger scale during magma evolution depends on the timescale of fractionation of melts and the surface area of mafic-felsic interfaces. It presumably affects redox conditions recorded by melt inclusions entrapped near the boundary during an initial stage of mixing.

We suggest that the observed redox process has implications for the mass transfer of $\mathrm{S}$ from mafic to felsic magma during underplating and/or recharge events. Here, $\mathrm{S}$ mass transfer occurs by diffusive transport or as a component of a magmatic volatile phase (MVP), and both mechanisms are dependent on the oxidation state of S (e.g., Wallace, 2005; Behrens and Stelling, 2011; Audétat and Simon, 2012; Burgisser et al., 2015; Parmigiani et al., 2016). Although more experiments are required, we also presume variations in $\mathrm{fO}_{2}$ at the magma-magma boundary layer under more reducing pre-mixing conditions, considering that the proposed mechanism, i.e. diffusion-induced electron hole imbalance, primarily depends on chemical differences, and less on the pre-mixing oxidation state of polyvalent elements (mainly $\mathrm{Fe}$, S). In such systems, changes in the $\mathrm{SO}_{2} / \mathrm{H}_{2} \mathrm{~S}$ ratio of the MVP are expected near the magma-magma interface (e.g., Burgisser et al., 2015), modifying its ability to scavenge Au from the melt (Zajacz et al., 2012). On the contrary, $\mathrm{Cu}$ exists in the MVP as a neutral Cu-alkali-Cl complex and its MVP/ melt partitioning is redox insensitive (Zajacz et al., 2012). Hence, the observed redox effects may moderate the $\mathrm{Cu} / \mathrm{Au}$ ratio of porphyry-type ore deposits that ultimately form by advection of a MVP into the overlying environment (Audétat and Simon, 2012)

\section{Acknowledgements}

This project was supported by a US National Science Foundation Collaborative Research grant to A.C.S. (EAR 1250239) and P.R. (EAR 1250414). P.R. also acknowledges support through EAR 1347880. This research used resources of the Advanced Photon Source, a US Department of Energy (DOE) Office of Science User Facility operated for the DOE Office of Science by Argonne National Laboratory under Contract No. DE-AC02-06CH11357. Brief discussions with Paul Ratteron, Reid Cooper and Dave Walker were helpful to refine our model of the redox gradient. We are grateful to Bruno Scaillet, anonymous reviewers, and the editorial advice of Helen Williams who helped to improve this manuscript.

Editor: Helen Williams

\section{Additional Information}

Supplementary Information accompanies this letter at www.geochemicalperspectivesletters.org/article1722 


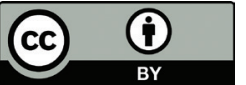

This work is distributed under the Creative Commons Attribution 4.0 License, which permits unrestricted use, distribution, and reproduction in any medium, provided the original author and source are credited. Additional information is available at http://www. geochemicalperspectivesletters.org/copyright-and-permissions.

Cite this letter as: Fiege, A., Ruprecht, P., Simon, A. (2017) A magma mixing redox trap that moderates mass transfer of sulphur and metals. Geochem. Persp. Let. 3, 190-199.

\section{References}

AnNEN, C., Blundy, J.D., Sparks, R.S.J. (2006) The Genesis of Intermediate and Silicic Magmas in Deep Crustal Hot Zones. Journal of Petrology 47, 505-539.

Audétat, A., Simon, A. (2012) Magmatic controls on porphyry Cu genesis. In: Hedenquist, J.W., Harris, M., Camus, F. (Eds.) Economic Geology Monograph in honor of Richard Sillitoe. Society of Economic Geologists Special Publication No. 16, 553-572.

BACON, C.R., Hirschmann, M.M. (1988) Mg/Mn partitioning as a test for equilibrium between coexisting Fe-Ti oxides. American Mineralogist 73, 57-61.

BACON, C.R. METZ, J. (1984) Magmatic inclusions in rhyolites, contaminated basalts, and compositional zonation beneath the Coso volcanic field, California. Contributions to Mineralogy and Petrology 85, 346-365.

BeHRENS, H., STELLING, J. (2011) Diffusion and redox reactions of sulfur in silicate melts. Reviews in Mineralogy and Geochemistry 73, 79-111.

BERGANTZ, G.W. (2000) On the dynamics of magma mixing by reintrusion: implications for pluton assembly processes. Journal of Structural Geology 22, 1297-1309.

Burgisser, A., ALLEtTI, M., SCAiLlet, B. (2015) Simulating the behavior of volatiles belonging to the $\mathrm{C}-\mathrm{O}-\mathrm{H}-\mathrm{S}$ system in silicate melts under magmatic conditions with the software D-Compress. Computers \& Geosciences 79, 1-14.

COOK, G.B., COOPER, R.F. (2000) Iron concentration and the physical processes of dynamic oxidation in an alkaline earth aluminosilicate glass. American Mineralogist 85, 397-406.

CoOPER, R.F. (2017) Redox Thermodynamics and Kinetics in Silicate Melts and Glasses-and Related Morphology/Texture. In: Richet, P. (Ed.) Encyclopedia of Glass Science, Technology, History and Culture. In press.

CoOper, R.F., FAnSElow, J.B., POKER, D.B. (1996) The mechanism of oxidation of a basaltic glass: chemical diffusion of network-modifying cations. Geochimica et Cosmochimica Acta 60 3253-3265.

Cooper, R.F., Everman, R.L., Hustoft, J.W., Dan Shim, S.H. (2010) Mechanism and kinetics of reduction of a $\mathrm{FeO}-\mathrm{Fe}_{2} \mathrm{O}_{3}-\mathrm{CaO}-\mathrm{MgO}$ aluminosilicate melt in a high- $\mathrm{CO}$-activity environment. American Mineralogist 95, 810-824.

DePAOLO, D.J. (1981) Trace element and isotopic effects of combined wallrock assimilation and frac tional crystallization. Earth and Planetary Science Letters 53, 189-202.

EVANS, K.A. (2006) Redox decoupling and redox budgets: Conceptual tools for the study of earth systems. Geology 34, 489-492.

Fiege, A., Ruprecht, P., Simon, A.C., Bell, A.S., Göttlicher, J., Newville, M., Lanzirotti, T, MOORE, G. (2017) Calibration of Fe XANES for high-precision determination of Fe oxidation state in glasses: Comparison of new and existing results obtained at different synchrotron radiation sources. American Mineralogist 102, 369-380.
FREER, R., HAUPTMAN, Z. (1978) Experimental-study of magnetite-titanomagnetite interdiffusion. Physics of the Earth and Planetary Interiors 16, 223-231.

Gaillard, F., SChmidt, B., MaCKwell, S., McCAmmon, C. (2003) Rate of hydrogen-iron redox exchange in silicate melts and glasses. Geochimica et Cosmochimica Acta 67, 2427-2441.

GHIORSO, M.S., EvanS, B.W. (2008) Thermodynamics of Rhombohedral Oxide Solid Solutions and a Revision of the Fe-Ti Two-Oxide Geothermometer and Oxygen-Barometer. American Journal of Science 308, 957-1039.

HiLDRETH, W. Moorbath, S. (1988) Crustal contributions to arc magmatism in the Andes of Central Chile. Contributions to Mineralogy and Petrology 98, 455-489.

MORETTI, R. (2005) Polymerisation, basicity, oxidation state and their role in ionic modelling of silicate melts. Annales Geophysicae 48, 583-608

Parmigiani, A., Fraroughi, S., Huber, C., Bachmann, O., Su, Y. (2016) Bubble accumulation and its role in the evolution of magma reservoirs in the upper crust. Nature 532, 492-495.

Perugini, D., Poli, G., Mazzuoli, R. (2003) Chaotic advection, fractals and diffusion during mixing of magmas: evidence from lava flows. Journal of Volcanology and Geothermal Research $124,255-279$.

Pichavant, M., Costa, F., Burgisser, A., Scaillet, B., Martel, C., Poussineau, S. (2007) Equilibration Scales in Silicic to Intermediate Magmas Implications for Experimental Studies. Journal of Petrology 48, 1955-1972

PISTONE, M., BLUNDY, J.D., BROOKER, R.A. (2016) Textural and chemical consequences of interaction between hydrous mafic and felsic magmas: an experimental study. Contributions to Mineralogy and Petrology 171, 8.

Ruprecht, P. BACHMANn, O. (2010) Pre-eruptive reheating during magma mixing at Quizapu volcano and the implications for the explosiveness of silicic arc volcanoes. Geology 38, 919-922.

Ruprecht, P., Bergantz, G.W., DufeK, J. (2008) Modeling of gas driven magmatic overturn Tracking of phenocryst dispersal and gathering during magma mixing. Geochemistry, Geophysics, Geosystems 9, doi:10.1029/2008GC002022.

WALLACE, P.J. (2005) Volatiles in subduction zone magmas: concentrations and fluxes based on melt inclusion and volcanic gas data. Journal of Volcanology and Geothermal Research 140, 217-240.

WALLACE, P., GeRLaCh, T.M. (1994) Magmatic vapor source for sulfur dioxide released during volcanic eruptions: Evidence from Mount Pinatubo. Science 265, 497-499

WATSON, E.B. (1982) Basalt contamination by continental crust: Some experiments and models. Contributions to Mineralogy and Petrology 80, 73-87.

Zajacz, Z., Candela, P.A., Piccoli, P.M., Wälle, M., Sanchez-Valle, C. (2012) Gold and copper in volatile saturated mafic to intermediate magmas: Solubilities, partitioning and implications for ore deposit formation. Geochimica et Cosmochimica Acta 91, 140-159.

ZHANG, Y., NI, H. (2010) Diffusion of H, C, and O Components in Silicate Melts. Reviews in Mineralogy and Geochemistry 72, 171-225. 